\title{
Physicochemical characteristics of monovarietal olive oil produced at Beni Tajjit, South-West of the region of Eastern Morocco
}

\author{
E. Khliil ${ }^{1}$, F. Mansouri ${ }^{1}$, A. Ben moumen ${ }^{1}$, H. Serghini-Caid ${ }^{1}$, \\ M. Berrabah ${ }^{2}$, E. Tahri ${ }^{1}$ \\ 1. Laboratoire de Biologie des Plantes et des Microorganismes, Faculté des sciences, \\ Université Mohammed Premier, Oujda, Morocco. \\ 2. Laboratoire de Chimie du Solide Minéral et Analytique, Faculté des sciences, \\ Université Mohammed Premier, Oujda, Morocco
}

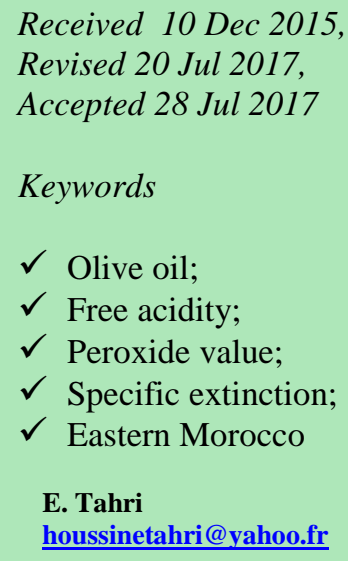

\begin{abstract}
This work aims to initiate a study on the quality of olive oil produced at the area of Beni Tajjit located in the south-west of eastern Morocco. Twenty olive cultivars were the subject of this study and some of their oil physicochemical characteristics were determined. The hierarchical analysis, taking into account the values of six physicochemical parameters considered as the most discriminating, reveals the potential existence of nine groups of olive oils of which three belong to the extra virgin category, one to the current category and five to the lampante category.
\end{abstract}

Abbreviations: BT: Beni Tajjit, IOC: International Olive Council, w: Weight.

\section{Introduction}

The Olive oil is one of the oldest vegetable oils mainly produced in countries around the Mediterranean Sea. Its consumption is increasing throughout the world due to the growing interest in the Mediterranean diet, of which olive oil is one of the main ingredients and which is often strongly correlated with the reduction of cardiovascular diseases and certain forms of cancer [1-4]. In addition to the lipid fraction itself, a tiny fraction (1-2\%) composed of tocopherols, phytosterols, pigments, phenolic and aromatic compounds, etc... would play an important role in the chemical, organoleptic and nutritional properties and stability of olive oil [5-10].

The International Olive Council (IOC) standards [11] and the Codex Alimentarius [12] distinguish four categories of virgin olive oil (Table 1): extra virgin, virgin, ordinary virgin and lampante virgin oils. The physicochemical characteristics (free acidity, peroxide index, absorbance in the UV) and sensory characteristics (positive and negative attributes) make olive oil of the lampante category, unlike the other categories, oil unfit for human consumption.

Table 1: Some physicochemical and organoleptic characteristics of virgin olive oil categories as defined by the IOC [11]. The free acidity is expressed as $\%$ of oleic acid (mass/mass). The peroxide value is given in meq $\mathrm{O}_{2} / \mathrm{kg}$ of olive oil. For other parameters, see explanations in the corresponding text.

\begin{tabular}{|c|c|c|c|c|}
\hline & \multicolumn{4}{|c|}{ Virgin olive categories } \\
\hline & Extra & Virgin & Ordinary & Lampante \\
\hline \multicolumn{5}{|l|}{ Physicochemical parameters } \\
\hline Free acidity & $\leq 0.8$ & $\leq 2.0$ & $\leq 3.3$ & $>3.3$ \\
\hline Peroxide value & $\leq 20$ & $\leq 20$ & $\leq 20$ & No limit \\
\hline UV specific extinction coefficient $K_{270}$ & $\leq 0.22$ & $\leq 0.25$ & $\leq 0.30 * *$ & - \\
\hline UV specific extinction coefficient $\mathrm{K}_{232}$ & $\leq 2.50 * *$ & $\leq 2.60 * *$ & - & - \\
\hline \multicolumn{5}{|l|}{ Sensory parameters } \\
\hline Median $(\mathrm{Me})$ of defects & $\mathrm{Me}=0$ & $0<\mathrm{Me} \leq 3.5$ & $3.5<\mathrm{Me} \leq 6.00 * *$ & $\mathrm{Me}>6.0$ \\
\hline Median $(\mathrm{Me})$ of fruitiness & $\mathrm{Me}>0$ & $\mathrm{Me}>0$ & - & - \\
\hline
\end{tabular}

** Or when the median of the defects is less than or equal to 3.5 and the median of the fruitiness is equal to 0. 
The free acidity of olive oil corresponds to the proportion of fatty acids found in the free state as a result of the lipolytic action of lipases of olives themselves and / or of lipolytic enzymes produced by microorganisms living on olives. This acidity is expressed by convention, in the case of olive oil, as oleic acid as it represents the main fatty acid [13]. Its ratio reflects the degree of stability of the oil and its susceptibility to rancidity.

The peroxide value is generally concerned with the number of active oxygen's in the organic chains of the fatty substances. It is expressed in meq $\mathrm{O}_{2}$ par $\mathrm{kg}$ of olive oil. It makes it possible, therefore, to evaluate the degree of oxidation of the unsaturated fatty acids. However, the only measure of the peroxide value is insufficient to get an exact idea of the oxidation state of oil $[14,15]$. The peroxide value is only an indicator of the onset of oxidation. It decreases with an advanced oxidation state where the peroxides, initially formed during the socalled primary oxidation phase, gradually generate volatile or non-volatile compounds (aldehydes, ketones, etc.) known as secondary oxidation.

The values of the absorptions at the specific wavelengths, 232 and $270 \mathrm{~nm}$, reflect the presence of conjugated dienes and trienes in the olive oil under examination. The production of these molecular species is linked to the oxidation phenomenon or to the refining process. Their rate is expressed through the values of the specific extinction coefficients denoted $\mathrm{K}_{232}$ and $\mathrm{K}_{270}$ [11]. Compounds of the oxidation of conjugated dienes contribute to the value of $\mathrm{K}_{232}$ while secondary oxidation compounds (alcohols, aldehydes, ketones, etc.) contribute to the $\mathrm{K}_{270}$ value [16]. These spectrophotometric studies in the ultraviolet range can therefore provide information on the quality of the fat, its state of preservation and also show the changes due to technological processes.

The aim of this work is to initiate a study on the physicochemical characteristics which will be complemented by a study on the sensory characteristics of olive oils produced at the Beni Tajjit site (Latitude: 32, Longitude: 3.4, Altitude: $1100 \mathrm{~m}$ above sea level, annual rainfall: about $200 \mathrm{~mm}$ ) located in the Southwest of the eastern region of Morocco. This study aims to complete the one that we have been carried out on the morphological identification of potentially existing olive varieties in the same site. We hope to arrive at the end to determine the quality of olive oils produced by each identified cultivars and by reference to the IOC standards. This study could also highlight the need to work to preserve the biodiversity of the olive orchard in both small and large scale.

\section{Experimental details}

\subsection{Plant material}

This study was carried out on the olive oil produced at the site of Beni Tajjit. Twenty olive cultivars, noted from BT1 to BT20, were involved which we have previously identified in the study of their morphological characteristics according to IOC standards [17]. This work was conducted during the two production seasons 2010/2011 and 2011/2012. For each fruiting season and each cultivar, two batches of two kilograms of olives were manually harvested at the mature stage (mid-December), then washed, weighed and subjected to a traditional extraction process comprising stages of grinding, mixing (These two stages lasted 40 minutes) and decantation (The temperature when we carried out this work did not exceed the $24^{\circ} \mathrm{C}$ ). The resulting olive oils were immediately kept in dark glass bottles and set aside in a cool place (about $10^{\circ} \mathrm{C}$.). Subsequently, they were the subject to physicochemical analyzes.

\subsection{Determination of fatty acid composition}

The fatty acid content of the olive oils was determined following their trans-methylation using a potassium hydroxide solution in methanol according to the standard method recommended by the IOC [18]. The fatty acid esters thus obtained were analyzed by gas chromatography (HP 6890 series GC equipped with a Supercowax $30 \mathrm{~m} \times 0.25 \mathrm{~mm}$ capillary column and an FID detector. Carrier gas: Nitrogen with a flow rate of $1.7 \mathrm{ml} / \mathrm{min}$. Injector and detector temperatures: 150 and $250^{\circ} \mathrm{C}$ respectively. Oven temperature: $20 \mathrm{~min}$ at $210^{\circ} \mathrm{C}$, rising between 210 and $245^{\circ} \mathrm{C}$ at a rate of $6^{\circ} \mathrm{C} / \mathrm{min}, 10 \mathrm{~min}$ at $245^{\circ} \mathrm{C}$ ).

\subsection{Determination of free acidity}

The free acidity of the various samples of olive oils was determined according to the AOCS method [19]. The free fatty acids were titrated with a potassium hydroxide solution in methanol in presence of phenolphthalein as a color indicator. The acidity is expressed as a percentage of oleic acid in olive oil (w/w).

\subsection{Determination of peroxide value}

The peroxide value was determined according to the AOCS method [19]. It is expressed in meq $\mathrm{O}_{2} / \mathrm{kg}$ of oil. The assay is based on the fact that in the acid medium the peroxides are reduced by the iodide ion $\left(\mathrm{I}^{-}\right)$in the absence of light. The iodine formed is then dosed with a solution of thiosulphate $\left(\mathrm{Na}_{2} \mathrm{~S}_{2} \mathrm{O}_{3}\right)$ of known concentration in the presence of starch pastes (EEC 2568/91, 1991). 


\subsection{Determination of specific extinction coefficients $K_{232}$ and $K_{270}$}

The ultraviolet specific extinction coefficients $\mathrm{K}_{232}$ and $\mathrm{K}_{270}$ were determined according to the IOC standard method [11]. The optic density readings using an UV-Visible Spectrophotometer were performed at the two wavelengths 230 and $270 \mathrm{~nm}$ against a control sample made of cyclohexane solvent.

\subsection{Hierarchical classification}

In order to determine the degree of resemblance between the different olive oils, a comparison was made on the basis of the contents of oleic and linoleic acids, the free acidity and peroxide values and the specific extinction coefficients $K_{232}$ and $K_{270}$. For each parameter, different classes were defined according to whether its values were low, medium, high or very high (Table 2). For the oleic and linoleic acid contents, four classes were chosen within the two ranges $55-83 \%$ and $3.5-21 \%$, respectively, as they were adopted by the IOC as characteristics of virgin olive oils [11]. For the other parameters, the limits of the different classes correspond to the limit values which the IOC uses for the classification of olive oils in the following categories: extra virgin, virgin, ordinary or lampante olive oil [11].

Table 2: Limits of different classes of physicochemical parameter values used in the hierarchical classification of the different olive oils harvested in Beni Tajjit area. The values of the oleic and linoleic acids are given in $\%$ in the various olive oils (w/w). The free acidity is expressed as $\%$ of oleic acid (w/w). The peroxide value is given in meq $\mathrm{O}_{2} / \mathrm{kg}$ of olive oil.

\begin{tabular}{|l|cccc|}
\hline Physicochemical parameters & Class 1 & Class 2 & Class 3 & Class 4 \\
\hline Oleic acid & $55-62$ & $62-69$ & $69-76$ & $76-83$ \\
\hline Linoleic acid & $3.5-8$ & $8-12.5$ & $12.5-17$ & $17-21$ \\
\hline Free acidity & $0-0.8$ & $0.8-2.0$ & $2-3.3$ & $>3.3$ \\
\hline Peroxide value & $0-7$ & $7-14$ & $14-20$ & $>20$ \\
\hline Specific extinction coefficient $\mathrm{K}_{232}$ & $0-2.50$ & $2.50-2.60$ & $>2.60$ & - \\
\hline Specific extinction coefficient $\mathrm{K}_{270}$ & $0-0.22$ & $0.22-0.25$ & $0.25-0.30$ & $>0.30$ \\
\hline
\end{tabular}

\section{Results and Discussion}

\subsection{Composition in fatty acids}

Results of the analyzes carried out on the olive oils derived from the twenty cultivars selected (Table 3) show that their fatty acid contents are within the limits recommended by the IOC for virgin olive oils [11]. Eight fatty acids are present, but at variable level. They are palmitic acid (C16:0), palmitoleic acid (C16:1), stearic acid (C18:0), oleic acid (C18:1), linoleic acid (C18:2), linolenic acid (C18:3), arachidic acid (C20:0) and gadoleic acid (C20:1). However, Myristic (C14:0), heptadecanoic (C17:0), heptadecenoic (C17:1), behenic (C22:0) and lignoceric (C24:0) acids were not detected in any olive oil. Oleic acid (C18: 1), with contents ranging from 68.3 to $75.8 \%$, followed, by far, by linoleic acid (C18:2) (from 11.2 to $15.1 \%)$ and palmitic acid (C16:0) (7.6 to $11.6 \%$ ) represent the major ones in all the studied oils.

As a comparison (Table 4), the oils derived from the southern part of the eastern region of Morocco have relatively similar compositions to olive oils produced in the northern part of the same region [20]. However, there are differences between them, as reflected in the levels of their high contents of linoleic acid and low contents of palmitic acid. Compared to other olive oils produced around the world [21-23], all cases (high and/or low contents) can occur.

Compared to the limits recommended by the IOC for virgin olive oils [11], one can note that:

- 19 out of 20 of the studied cultivars gave an olive oil relatively rich in oleic acid. The grades could be ranked in the third quarter of the range 55-83\% recommended by the IOC for virgin olive oils.

- 18 out of 20 of the studied oils are characterized by high linoleic acid levels which exceeded $12.5 \%$.

- The content in palmitic acid remained near the lower limit of the $7.5-20 \%$ range as recommended by the IOC for virgin olive oils.

The relative richness of oleic acid in studied olive oils could be one of their most important characteristics. The high content of monounsaturated fatty acids, especially oleic acid, confers, to the olive oil its originality and its virtues in terms of effect on health $[3,4]$.

The presence of linoleic acid in most of oils at relatively high levels could reduce their storage time by promoting their oxidation which produces products having conjugated double bonds leading to the production of unpleasant volatile substances, in particular, those responsible for their rancidity [24, 25]. 
Table 3: Fatty acids composition of the different oils produced from twenty cultivars of Beni Tajjit: (C14:0): Myristic acid,(C16:0): Palmitic acid, (C16:1): Palmitoleic acid, (C17:0): Heptadecanoic acid, (C17:1): Heptadecenoic acid, (C18:0) : Stearic acid, (C18:1) : Oleic acid, (C18:2) : Linoleic acid, (C18:3) : Linolenic acid, (C20:0) : Arachidic acid, (C20:1) : Gadoleic acid (or Eicosenoic acid), (C22:0) : Behenic acid, (C24:0) : Lignoceric acid. Each value represents an average of two different analyzes carried out on the olive oils produced during the two producing seasons 2010/2011 and 2011/2012. The limit values for the levels of each fatty acid in virgin olive oils as defined by the IOC [11] are presented in the last line.

\begin{tabular}{|c|c|c|c|c|c|c|c|c|c|c|c|c|c|}
\hline \multirow[b]{2}{*}{ Cultivars } & \multicolumn{13}{|c|}{ Fatty acids (\%) } \\
\hline & C14:0 & C16:0 & C16:1 & C17:0 & C17:1 & C18:0 & C18:1 & C18:2 & C18:3 & C20:0 & C20:1 & C22:0 & C24:0 \\
\hline BT1 & ND & 9.41 & 0.78 & $\mathrm{ND}$ & $\mathrm{ND}$ & 2.5 & 71.84 & 13.95 & 0.92 & 0.29 & 0.31 & $\mathrm{ND}$ & ND \\
\hline BT2 & ND & 10.13 & 0.76 & ND & ND & 2.6 & 71.67 & 13.36 & 0.88 & 0.29 & 0.31 & ND & ND \\
\hline BT3 & $\mathrm{ND}$ & 10.32 & 0.82 & ND & ND & 2.49 & 71.8 & 13.05 & 0.85 & 0.3 & 0.37 & $\mathrm{ND}$ & ND \\
\hline BT4 & ND & 10.82 & 0.84 & ND & ND & 2.56 & 71.84 & 14.98 & 0.95 & 0.27 & 0.3 & ND & ND \\
\hline BT5 & ND & 10.97 & 0.54 & ND & ND & 2.58 & 71.19 & 13.38 & 0.89 & 0.2 & 0.24 & $\mathrm{ND}$ & $\mathrm{ND}$ \\
\hline BT6 & ND & 11.63 & 0.87 & ND & ND & 2.51 & 68.28 & 15.14 & 1.03 & 0.26 & 0.27 & ND & $\mathrm{ND}$ \\
\hline BT7 & ND & 10.74 & 0.89 & ND & $\mathrm{ND}$ & 2.31 & 71.24 & 13.31 & 0.97 & 0.26 & 0.27 & $\mathrm{ND}$ & ND \\
\hline BT8 & ND & 9.85 & 0.89 & ND & ND & 2.15 & 74.55 & 11.21 & 0.83 & 0.24 & 0.28 & ND & ND \\
\hline BT9 & ND & 10.51 & 0.95 & ND & ND & 2.57 & 69.78 & 14.65 & 0.95 & 0.29 & 0.3 & ND & ND \\
\hline BT10 & ND & 9.09 & 0.61 & ND & ND & 2.04 & 74.05 & 12.82 & 1 & 0.16 & 0.22 & ND & ND \\
\hline BT11 & ND & 7.65 & 0.7 & ND & ND & 1.89 & 75.86 & 12.48 & 1.06 & 0.16 & 0.2 & ND & ND \\
\hline BT12 & ND & 9.87 & 0.64 & ND & ND & 2.5 & 70.82 & 14.85 & 0.91 & 0.21 & 0.2 & ND & ND \\
\hline BT13 & ND & 10.41 & 0.72 & ND & ND & 2.08 & 71.05 & 14.37 & 0.84 & 0.28 & 0.25 & ND & ND \\
\hline BT14 & ND & 11.65 & 0.83 & ND & ND & 1.92 & 71.1 & 12.78 & 0.85 & 0.51 & 0.36 & $\mathrm{ND}$ & ND \\
\hline BT15 & ND & 9.34 & 0.79 & ND & ND & 2.01 & 72.16 & 14.19 & 0.92 & 0.31 & 0.28 & ND & ND \\
\hline BT16 & ND & 10.14 & 0.74 & ND & ND & 2.89 & 70.01 & 14.96 & 0.86 & 0.19 & 0.21 & ND & ND \\
\hline BT17 & ND & 10,62 & 0.86 & ND & ND & 2.43 & 71.13 & 13.62 & 0.81 & 0.26 & 0.27 & ND & ND \\
\hline BT18 & $\mathrm{ND}$ & 10.56 & 0.92 & ND & ND & 2.51 & 71.06 & 13.42 & 0.93 & 0.28 & 0.32 & $\mathrm{ND}$ & ND \\
\hline BT19 & ND & 11.07 & 0.79 & ND & ND & 2.45 & 71.14 & 12.79 & 0.93 & 0.52 & 0.32 & $\mathrm{ND}$ & ND \\
\hline ВT20 & ND & 9.84 & 0.87 & ND & ND & 2.18 & 71.08 & 14.51 & 0.81 & 0.49 & 0.21 & ND & ND \\
\hline $\begin{array}{c}\text { IOC values } \\
(\%)\end{array}$ & $\leq 0,05$ & 7,5-20 & $0,3-3,5$ & $\leq 0,3$ & $\leq 0,3$ & $0,5-5$ & $\mid 55-83$ & $3,5-21$ & $\leq 1,0$ & $\leq 0,6$ & $\leq 0,4$ & $\leq 0,2$ & $\leq 0,2$ \\
\hline
\end{tabular}

ND: Not detected

Table 4: Percentage of palmitic, oleic and linoleic acids in olive oils produced in both, northern part of eastern Morocco and other cultivars throughout the world (Arbequina, Frantoio, Koroneiki, Leccino).

\begin{tabular}{|l|ccccc|}
\hline Fatty acids & Eastern Morocco & Arbequina & Frantoio & Koroneiki & Leccino \\
& {$[20]$} & {$[21]$} & {$[22]$} & {$[21]$} & {$[23]$} \\
\hline Palmitic acid (C16:0) (\%) & $10.1-13.5$ & 17.5 & 10.9 & 11.6 & 13.7 \\
Oleic acid (C18:1) (\%) & $73.2-76.5$ & 58.8 & 78.3 & 75.5 & 75.6 \\
Linoleic acid (C18:2)(\%) & $8.7-9.3$ & 12.9 & 6.7 & 8.5 & 5.6 \\
\hline
\end{tabular}

The differences in fatty acid levels that can be noted between the olive oils of the twenty cultivars or those produced by other ones can be attributed, as indicated in the literature, to various factors of which two are the main ones: the variety and the stage of maturity of the olives [26,27]. These differences could also be attributed to agro-climatic conditions $[28,29]$, irrigation $[30,31]$ and technical aspects of extracting olive oil [32].

\subsection{Physicochemical characteristics}

Four physicochemical parameters were studied: the free acidity, the peroxide index and the specific extinction coefficients to the wavelengths 232 and 270nm (K232 and K270) (Table 5).

The content of free acidity that we have recorded in all our olive oils (Values below the limit value, $0.8 \%$, recommended by the IOC for extra virgin olive oils [11]) could be attributed in particular to the freshness of olives used in the extraction and to the method of their harvesting which was manual. These means would at least have helped to minimize the possible hydrolysis reactions of enzymatic or chemical type leading to the 
release of fatty acids from their initial glyceride forms [33-35]. For the other physicochemical parameters, peroxide values and specific extinction coefficients $\mathrm{K}_{232}$ and $\mathrm{K}_{270}$, the values obtained exceed largely the limits recommended by the IOC for virgin olive oils [11] in most cases. Olive oils produced in the north of the region $[36,37]$ or in other localities [38] in Morocco remain, on the contrary, below these limits.

Taking into account the values of the four physicochemical parameters, and by reference to the commercial standard applied by the IOC to olive oil [11], it appears that among the 20 studied olive oils, six (BT2, BT3, BT4, BT5, BT9 and BT11) would exhibit the characteristics of an extra virgin olive oil, one (BT1) of the ordinary category and thirteen (BT6, BT7, BT8, BT10, BT12, BT13, BT14, BT15, BT16, BT17, BT18, BT19 and BT20) of the lampante category. Higher values in peroxide and / or of the specific extinction coefficients were due to a state of advanced oxidation of certain oils of the lampante category.

Table 5: Classification of the different olive oils obtained from the twenty cultivars according to their physicochemical characteristics. Each value represents an average of two different analyzes carried out on the olive oils of each of the two harvesting season 2010/2011 and 2011/2012. The free acidity (FA) is expressed in g of oleic acid per 100g of olive oil. The peroxide value (PV) is given in meq $\mathrm{O}_{2}$ per $\mathrm{kg}$ of olive oil. $\mathrm{K}_{232}$ and $\mathrm{K}_{270}$ correspond to the UV specific extinction coefficients.

\begin{tabular}{|c|cccc|c|}
\hline & \multicolumn{3}{|c|}{ Physicochemical parameters } & Olive oil \\
Cultivars & FA & PV & K $_{\mathbf{2 3 2}}$ & $\mathbf{K}_{\mathbf{2 7 0}}$ & \\
\cline { 2 - 5 } BT2 & 0.39 & 7.9 & 2.02 & 0.15 & \\
BT3 & 0.23 & 14.9 & 1.63 & 0.12 & \\
BT4 & 0.25 & 17.9 & 1.91 & 0.16 & Extra virgin \\
BT5 & 0.30 & 18.9 & 2.23 & 0.21 & \\
BT9 & 0.30 & 13.9 & 2.20 & 0.16 & \\
BT11 & 0.28 & 16.9 & 2.12 & 0.18 & \\
\hline- & - & - & - & - & Virgin \\
\hline BT1 & 0.28 & 16.9 & 2.7 & 0.28 & Ordinary \\
\hline BT6 & 0.54 & 38.8 & 2.92 & 0.45 & \\
BT7 & 0.32 & 31.6 & 2.98 & 0.46 & \\
BT8 & 0.29 & 24.8 & 2.76 & 0.35 & \\
BT10 & 0.27 & 21.9 & 2.81 & 0.31 & \\
BT12 & 0.20 & 10.9 & 2.10 & 0.47 & \\
BT13 & 0.23 & 19.9 & 2 & 0.47 & \\
BT14 & 0.24 & 10.9 & 2.11 & 0.47 & Lampante \\
BT15 & 0.24 & 10.9 & 2.10 & 0.47 & \\
BT16 & 0.20 & 11 & 2.10 & 0.47 & \\
BT17 & 0.20 & 10.9 & 2 & 0.47 & \\
BT18 & 0.24 & 10.9 & 2 & 0.47 & \\
BT19 & 0.23 & 11 & 2.10 & 0.47 & \\
BT20 & 0.20 & 10.9 & 2.10 & 0.47 & \\
& & & & \\
\end{tabular}

\subsection{Hierarchical classification}

In order to determine the resemblance degree between all the studied olive oils, we have been based, in the first step, on the comparison of belonging classes (review the precision in table 2) of their most important physicochemical parameters: Oleic and linoleic acids, free acidity, peroxide index and specific extinction coefficients K232 and K270. Results reported in Table 6 show so some uniformity in the case of three parameters, oleic acid, linoleic acid and free acidity, but they show some multiplicity in the case of the three remaining ones, peroxide, K232 and K270.

A further treatment of the results presented above in the table 6 in order to compare different BT olive oils to each other shows that some oils appear to be similar (zero difference) (Case of BT2 and BT9 for example) whereas others can have up to five differences in their physicochemical characteristics (Case of BT6 and BT11) (Table 7).

Hierarchical analysis (Figure 1) based on the physicochemical class values presented above in the table 7 shows that nine groups of homogeneous olive oils can be formulated (Table 8): Group I made of sample BT2 and BT9, Group II made of BT3, BT4 and BT5, Group III consisting of sample BT11, Group IV consisting of the sample BT1, Group V consisting of the sample BT6, Group VI made of sample BT10 and BT7, Group VII consisting of the sample BT8, Group VIII made of sample BT12, BT14, BT15, BT16, BT17, BT18, BT19 and BT20, and finally Group IX consisting of the sample BT13. 
Table 6: Belonging classes of six physicochemical parameters (Oleic and linoleic acids, free acidity, peroxide, and specific extinction coefficients $\mathrm{K}_{232}$ and $\mathrm{K}_{270}$ ) characterized the twenty olive oils from Beni Tajjit site.

\begin{tabular}{|c|cccccc|}
\cline { 2 - 7 } \multicolumn{1}{c|}{} & \multicolumn{7}{c|}{ Physicochemical parameters } \\
\hline Cultivars & Oleic acid & $\begin{array}{c}\text { Linoleic } \\
\text { acid }\end{array}$ & $\begin{array}{c}\text { Free } \\
\text { acidity }\end{array}$ & $\begin{array}{c}\text { Peroxide } \\
\text { value }\end{array}$ & $\mathbf{K}_{\mathbf{2 3 2}}$ & $\mathbf{K}_{\mathbf{2 7 0}}$ \\
\hline BT1 & 3 & 3 & 1 & 3 & 3 & 3 \\
\hline BT2 & 3 & 3 & 1 & 2 & 1 & 1 \\
\hline BT3 & 3 & 3 & 1 & 3 & 1 & 1 \\
\hline BT5 & 3 & 3 & 1 & 3 & 1 & 1 \\
\hline BT6 & 3 & 3 & 1 & 3 & 3 & 1 \\
\hline BT7 & 3 & 3 & 1 & 4 & 3 & 4 \\
\hline BT8 & 3 & 3 & 1 & 4 & 3 & 4 \\
\hline BT9 & 3 & 2 & 1 & 4 & 1 & 1 \\
\hline BT10 & 3 & 3 & 1 & 2 & 1 & 1 \\
\hline BT11 & 3 & 2 & 1 & 3 & 1 & 4 \\
\hline BT12 & 3 & 3 & 1 & 2 & 1 & 4 \\
\hline BT13 & 3 & 3 & 1 & 3 & 1 & 4 \\
\hline BT14 & 3 & 3 & 1 & 2 & 1 & 4 \\
\hline BT15 & 3 & 3 & 1 & 2 & 1 & 4 \\
\hline BT16 & 3 & 3 & 1 & 2 & 1 & 4 \\
\hline BT17 & 3 & 3 & 1 & 2 & 1 & 4 \\
\hline BT18 & 3 & 3 & 1 & 2 & 1 & 4 \\
\hline BT19 & 3 & 3 & 1 & 2 & 1 & 4 \\
\hline BT20 & 3 & 3 & 1 & 2 & & 4 \\
\hline & & & & & 1 & 1 \\
\hline
\end{tabular}

Table 7: Number of classes of physicochemical parameters differentiating each oil from others.

\begin{tabular}{|c|c|c|c|c|c|c|c|c|c|c|c|c|c|c|c|c|c|c|c|c|}
\hline \multicolumn{10}{c|}{ Cultivars (BT) } \\
\hline Cultivars & $\mathbf{1}$ & $\mathbf{2}$ & $\mathbf{3}$ & $\mathbf{4}$ & $\mathbf{5}$ & $\mathbf{6}$ & $\mathbf{7}$ & $\mathbf{8}$ & $\mathbf{9}$ & $\mathbf{1 0}$ & $\mathbf{1 1}$ & $\mathbf{1 2}$ & $\mathbf{1 3}$ & $\mathbf{1 4}$ & $\mathbf{1 5}$ & $\mathbf{1 6}$ & $\mathbf{1 7}$ & $\mathbf{1 8}$ & $\mathbf{1 9}$ & $\mathbf{2 0}$ \\
\hline BT1 & 0 & & & & & & & & & & & & & & & & & & & \\
\hline BT2 & 3 & 0 & & & & & & & & & & & & & & & & & & \\
\hline BT3 & 2 & 1 & 0 & & & & & & & & & & & & & & & & & \\
\hline BT4 & 2 & 1 & 0 & 0 & & & & & & & & & & & & & & & & \\
\hline BT5 & 2 & 1 & 0 & 0 & 0 & & & & & & & & & & & & & & & \\
\hline BT6 & 3 & 4 & 4 & 4 & 4 & 0 & & & & & & & & & & & & & & \\
\hline BT7 & 2 & 3 & 3 & 3 & 3 & 1 & 0 & & & & & & & & & & & & & \\
\hline BT8 & 3 & 4 & 4 & 4 & 4 & 2 & 1 & 0 & & & & & & & & & & & & \\
\hline BT9 & 3 & 0 & 1 & 1 & 1 & 4 & 3 & 4 & 0 & & & & & & & & & & & \\
\hline BT10 & 2 & 3 & 3 & 3 & 3 & 1 & 0 & 1 & 3 & 0 & & & & & & & & & & \\
\hline BT11 & 3 & 2 & 1 & 1 & 1 & 5 & 4 & 3 & 2 & 4 & 0 & & & & & & & & & \\
\hline BT12 & 3 & 1 & 2 & 2 & 2 & 3 & 2 & 3 & 1 & 2 & 3 & 0 & & & & & & & & \\
\hline BT13 & 2 & 2 & 1 & 1 & 1 & 3 & 2 & 3 & 2 & 2 & 2 & 1 & 0 & & & & & & & \\
\hline BT14 & 3 & 1 & 2 & 2 & 2 & 3 & 2 & 3 & 1 & 2 & 3 & 0 & 1 & 0 & & & & & & \\
\hline BT15 & 3 & 1 & 2 & 2 & 2 & 3 & 2 & 3 & 1 & 2 & 3 & 0 & 1 & 0 & 0 & & & & & \\
\hline BT16 & 3 & 1 & 2 & 2 & 2 & 3 & 2 & 3 & 1 & 2 & 3 & 0 & 1 & 0 & 0 & 0 & & & & \\
\hline BT17 & 3 & 1 & 2 & 2 & 2 & 3 & 2 & 3 & 1 & 2 & 3 & 0 & 1 & 0 & 0 & 0 & 0 & & & \\
\hline BT18 & 3 & 1 & 2 & 2 & 2 & 3 & 2 & 3 & 1 & 2 & 3 & 0 & 1 & 0 & 0 & 0 & 0 & 0 & & \\
\hline BT19 & 3 & 1 & 2 & 2 & 2 & 3 & 2 & 3 & 1 & 2 & 3 & 0 & 1 & 0 & 0 & 0 & 0 & 0 & 0 & \\
\hline BT20 & 3 & 1 & 2 & 2 & 2 & 3 & 2 & 3 & 1 & 2 & 3 & 0 & 1 & 0 & 0 & 0 & 0 & 0 & 0 & 0 \\
\hline
\end{tabular}

The difference between these nine olive oil groups, with respect to each other, ranges from one (Case of group I and group II for example) and five (case of group III and group V) different physicochemical parameter values (Table 9).

Looking at their physicochemical characteristics (review Table 5), oils extracted from olive groups I to III can classified as extra virgin, from olive group IV as ordinary category and from olive groups V to IX as lampante category. The quality of each olive oil may constitute an endogenous characteristic and its oxidative stability would depend, among other factors, on satiety of phenolic compounds and tocopherols and the composition in fatty acids and in carotenoids and chlorophyll pigments [39-43]. However, the chemical composition and organoleptic properties could be modified by different factors such as cultivation practices, environmental 
conditions (mineral nutrition, temperature, light, water availability, etc.), the olive maturity degree and the processus used in its extraction $[44,45]$.

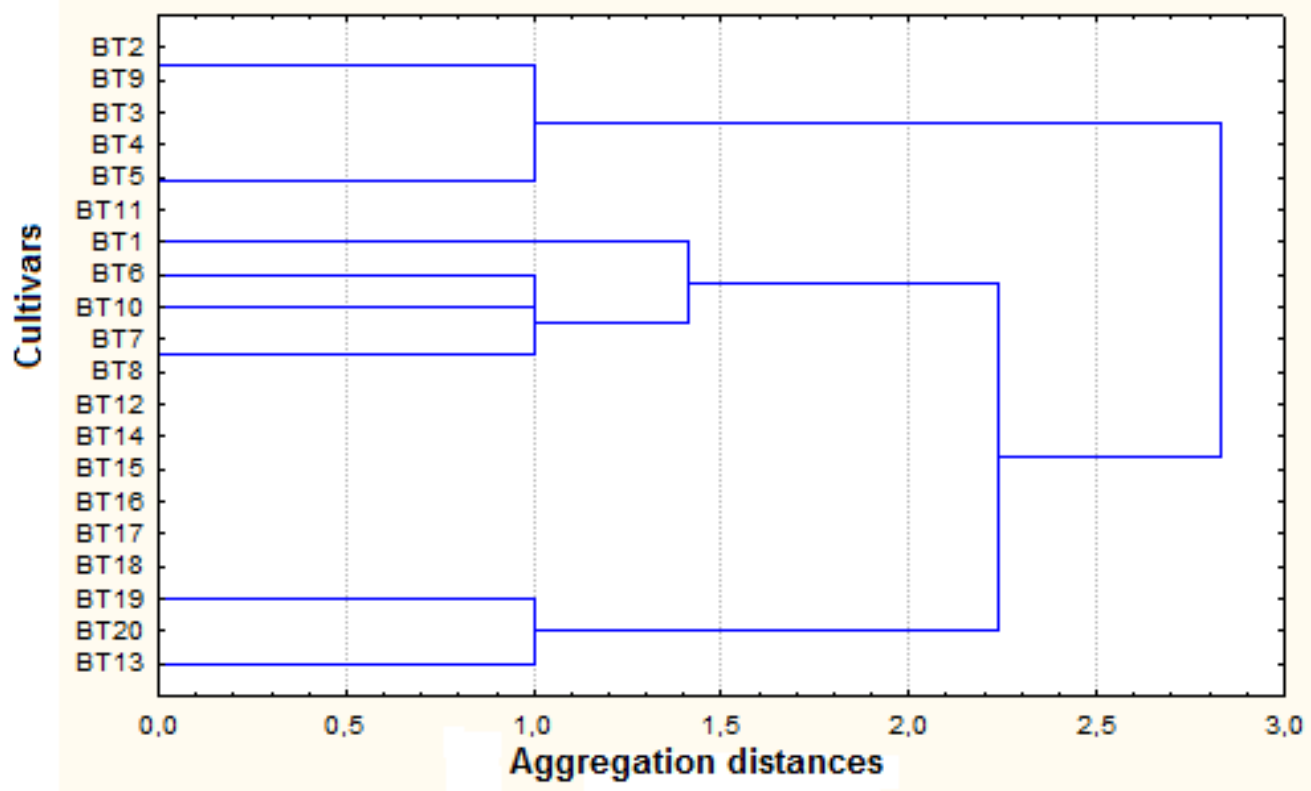

Figure 1: Hierarchical clustering dendrogram of the Beni Tajjit olive oils based on the square Euclidean distances calculated from the physicochemical class values.

Table 8: Characteristics of the nine groups of olive oil from point of view class of belonging of their physicochemical parameters (oleic and linoleic acids contents, free acidity, peroxide value and the specific extinction coefficients $\mathrm{K}_{232}$ and $\mathrm{K}_{270}$ values) values.

\begin{tabular}{|c|c|c|c|c|c|c|c|}
\hline \multirow{2}{*}{$\begin{array}{l}\text { Olive oil } \\
\text { groups }\end{array}$} & \multirow[b]{2}{*}{ Olive cultivars } & \multicolumn{6}{|c|}{ Physicochemical parameter classes } \\
\hline & & Oleic acid & $\begin{array}{c}\text { Linoleic } \\
\text { acid }\end{array}$ & $\begin{array}{l}\text { Free } \\
\text { acidity }\end{array}$ & $\begin{array}{l}\text { Peroxide } \\
\text { value }\end{array}$ & $\mathbf{K}_{\mathbf{2 3 2}}$ & $\mathbf{K}_{270}$ \\
\hline $\mathbf{I}$ & BT2; BT9 & 3 & 3 & 1 & 2 & 1 & 1 \\
\hline II & BT3; BT4; BT5 & 3 & 3 & 1 & 3 & 1 & 1 \\
\hline III & BT11 & 3 & 2 & 1 & 3 & 1 & 1 \\
\hline IV & BT1 & 3 & 3 & 1 & 3 & 3 & 3 \\
\hline $\mathrm{V}$ & BT6 & 2 & 3 & 1 & 4 & 3 & 4 \\
\hline VI & BT10; BT7 & 3 & 3 & 1 & 4 & 3 & 4 \\
\hline VII & BT8 & 3 & 2 & 1 & 4 & 3 & 4 \\
\hline VIII & $\begin{array}{l}\text { BT12; BT14; BT15; BT16; } \\
\text { BT17; BT18; BT19; BT20 }\end{array}$ & 3 & 3 & 1 & 2 & 1 & 4 \\
\hline IX & BT13 & 3 & 3 & 1 & 3 & 1 & 4 \\
\hline
\end{tabular}

Table 9: Number of physicochemical parameters classes differentiating the nine olive oil groups from one another.

\begin{tabular}{|c|c|c|c|c|c|c|c|c|c|}
\cline { 2 - 12 } \multicolumn{1}{c|}{} & \multicolumn{9}{c|}{ Olive oil groups } \\
\hline Olive oil groups & I & II & III & IV & V & VI & VII & VIII & IX \\
\hline I & 0 & & & & & & & & \\
\hline II & 1 & 0 & & & & & & & \\
\hline III & 2 & 1 & 0 & & & & & & \\
\hline IV & 3 & 2 & 3 & 0 & & & & & \\
\hline V & 4 & 4 & 5 & 3 & 0 & & & & \\
\hline VI & 3 & 3 & 4 & 2 & 1 & 0 & & & \\
\hline VII & 4 & 4 & 3 & 3 & 2 & 1 & 0 & & \\
\hline VIII & 1 & 2 & 3 & 3 & 3 & 2 & 3 & 0 & \\
\hline IX & 2 & 1 & 2 & 2 & 3 & 2 & 3 & 1 & 0 \\
\hline
\end{tabular}

Certain traditional cultivation practices, followed at the Beni Tajjit site can reduce the quality of the oils. For example, fertilization method based mainly on the use of manure may lead to an excess of some mineral 
elements and to the deficiency of others. Both situations could affect olive production quantitatively and qualitatively [46-48].

The widespread presence of the olive fly (Bactrocera oleae) in Beni Tajjit, which is due to the lack the use of pesticides, could be another factor involved in reducing the quality of olive oil produced which will be characterized by high values of free acidity and peroxide, along high specific extinction coefficients and low phenolic compounds [49-52].

The late harvest at Beni Tajjit which is aimed to maximize the yields of the oil, could constitute an additional factor adversely affecting the the quality of the oils produced. In this context, it is well known that over-ripened olives give known oil for its susceptibility to deterioration having an oxidative origin [53,54]. By adopting the optimum harvest date (A maturity index of 2.5 to 4.5 is usually used for most olive oils [55]), the oils obtained would be of superior quality, due in particular to their composition in triacylglycerols (low content of polyunsaturated fatty acids) and in antioxidant compounds (polyphenols and tocopherols) [56].

\section{Conclusions}

Through this work we were able to determine some physicochemical characteristics concerning twenty olive oils currently produced in Beni Tajjit. They are generally characterized by their relatively high levels of oleic acid but also linoleic acid which could contribute highly to their oxidative instability. Only six olive oils samples among a group of twenty possess the characteristics of an extra virgin olive oil, the rest (thirteen) is considered as the lampante category. Late harvesting at the Beni Tajjit site added to the lack of the use of fertilizer and pest control, including the olive fly, could be potentially responsible for the poor quality of the olive oils. A wider and deeper study could contribute to the improvement of the quality of the olive oils produced in this region.

\section{References}

1. Ryan D., Robards K., Analyst. 123 (1998) 31-44.

2. Trichopoulou A., Costacou T., Bamia C., Trichopoulos D. N., Engl. J. Med. 348 (2003) 2599-2608.

3. Knoops K.T., de Groot L.C., Kromhout D., J. Am. Med. Assoc. 292 (2004) 1433-1439.

4. Artajo L.S., Romero M.P., Morelloa J.R., Motilva M.J., J. Agric. Food Chem. 54 (2006) 6079-6088.

5. Kiritsakis A.K., Nanos G.D., Polymenoupoulos Z., Thomai T., Sfakiotakis E.Y., J. Am. Oil Chem. Soc. 75 (1998) 721-724.

6. Cert A., Moreda W., Perez-Camino M.C., J. Chromatography. 148 (2000) 131-148.

7. Vichi S., Castellote A.I., Pizzale L., Conte L.S., Buxaderas S., Lopez-Tamames E., J. Agric. Food Chem. 51 (2003) 6572-6577.

8. Boskou D. Olive Oil: Chemistry and Technology. Am. Oil Chem. Soc. Press, Champaign, IL, USA, (2006).

9. Kalua C. M., Allen M. S., Bedgood D. R., Bishop A. G., Prenzler P. D., Robards K., Food Chem. 100 (2007) 273-286.

10. Martinez-Vidal J.L., Garrido-Frenich A., Escobar-Garcia M.A., Romero-Gonzales R., Chromatographia 65 (2007) 695-699.

11. Conseil Oléicole Internatinal. COI/T.15/NC (2/Rév. 10) (2001).

12. Codex Alimentarius 8 (2003) 25-39.

13. Pardo J.E., Cuesta M.A., Alvarruiz A., Food Chem. 100 (2007) 977-984.

14. Frenot M., Vierling E., Science des aliments, Doin, (2001).

15. Van Eys J.E., Offner A., Bach A., Global Animal Nutrition Solutions (2005) 1-12.

16. Kiritsakis A., Kanavouras A., Kiritsakis K., Eur. J. Lipid Sci. Technol 104 (2002) 628-638.

17. Conseil Oléicole Intenational. Méthodologie de caractérisation primaire des variétés d'olivier (RESGENT96/97). Ed. Union Européenne-Conseil Oléicole International, Madrid, España, 1997.

18. Conseil oléicole International, COI/T.20/Doc. $\mathrm{N}^{\mathrm{o}} 24$. (2001).

19. Free Fatty Acids: Official Method, Ca 5a-40, J. Amer. Oil Chem. Soc. 1997.

20. Tanouti K., Serghini-Caid H., Abid M., Mihamou A., Khiar M., Hachem M. E., Bahetta Y., Elamrani A., Les technologies de laboratoire 23 (2011) 58-63.

21. Allalout A., Krichene D., Methenni K., Taamalli A., Oueslati I., Daoud D., Sci. Hort. 120 (2009) 77-83.

22. Paz Aguilera M., Beltran G., Ortega D., Fernandez A., Jimenez A., Uceda M., Food Chem. 89 (2005) $387-$ 391. 
23. Skevin D., Rade D., Strucelj D., Mokrovãak Z., Nederal S., Benãiç D., Eur. J. Lipid Sci. Technol. 105 (2003) 536-541.

24. Solinas M., Proceedings of the Problematiche qualitative dell'olio di oliva Congress, Sassari, Italy, (1990) 23-55.

25. Luning P.A., Carey A.T., Roozen J.P., Wichers H.J., J. Agric. Food Chem. 43 (1995) 1493-1500.

26. Romani A., Mulinacci N., Pinelli P., Vincieri F.F., Cimato A., J. Agric. Food Chem. 47 (1999) 964-967.

27. Aparicio R., Luna G., Eur. J. Lipid Sci. Technol. 104 (2002) 614-627.

28. Judde A., OCL. 11 (2004) 414-418.

29. Vinha A.F., Ferreres F., Silva B.M., Valentão P., Gonçalves A., Pereira J.A., Oliveira M.B., Seabra R.M., Andrade P.B., Food Chem. 89 (2005) 561-568.

30. Patumi M., D'andria R., Marsilio V., Fontanazza G., Morelli G., Lanza B., Food Chem. 77 (2002) 27-34.

31. Tovar M.J., Romero M.P., Alegre S., Girona J., Motilva M.J., J. Sci. Food Agric. 82 (2002) 1755-1763.

32. Covas M.I., Inflammopharmacology 16 (2008) 216-218.

33. Abaza L., Msallem M., Daoud D., Zarrouk M., OCL. 9 (2002) 174-79.

34. Servili M., Baldioli M., Montedoro G.F., Acta Hortic. 356 (1994) 331-336.

35. Capella P., Fedeli E., Bonaga G., Lerker G., Manuale degli Oli e dei Grassi, Tecniche Nuove, Milano, Italy, (1997).

36. Tanouti K., Elamrani A., Serghini-Caid H., Khalid A., Bahetta Y., Benali A., Harkous M., Khiar M., Les technologies de laboratoire 5 (2010) 18-26.

37. Mansouri F., Ben moumen A., Richard G., Fauconnier M.L., Sindic M., Serghini-Caid H., Elamrani A., J. Mater. Environ. Sci. 6 (2015) 2322-2329.

38. Meftah H., Latrache H., Hamadi F., Hanine H., Zahir H., El louali M., J. Mater. Environ. Sci. 5 (2014) 641-646.

39. Aparicio R., Roda L., Albi M.A., Gutiérrez F., J. Agr. Food Chem. 47 (1999) 4150-4155.

40. Baldioli M., Servili M., Perretti G., Montedoro G.F., J. Amer. Oil Chem. Soc. 73 (1996) 1589-1593.

41. Beltrán G., Jiménez A., Aguilera M.P., Uceda M., Grasas y aceites 51 (2000) 320-324.

42. Tsimidou M., Papadopoulos G., Boskou D., Food Chem. 45 (1992) 141-144.

43. Vázquez A., Janer C., Janer M.L., Grasas y aceites 24 (1973) 350-357.

44. Tovar M.J., Motilva M.J., Romero M.P., J. Agric. Food Chem. 49 (2001) 5502-5508.

45. Kiritsakis A.K., Olive Oil from the Tree to the Table", Food \& Nutrition Press, Inc. Trumbull, Connecticut, U.S.A. (1998).

46. Fernández-Escobar R., Beltrán G., Sánchezzamora M.A., García-Novelo J., Aguilera M. P., Uceda M., Hort. Sc. 41 (2006) 215-219.

47. Fernández-Escobar R., Olivae 109 (2008) 13-22.

48. Simoes P., Pinheiro-Alves C., Cordeiro A.M., Marcelo M.E., Acta Hort. 586 (2002) 337-340.

49. Delrio G., Lentini A., Vacca V., Serra G., Riv. Ital. Sostanze Grasse 72 (1995) 5-9.

50. Parlati M.V., Longo S., Benfato D., Acta Hort. 286 (1990) 379-382.

51. Parlati M.V., Mulè R., Longo S., Patti I., Benfatto D., Sichel D., L'Informatore Agrario 36 (1992) 69.

52. Zunin P., Evangelisti F., Tiscornia E., Riv. Ital. Sostanze Grasse 70 (1993) 477-482.

53. Al-Maaitah M. I., Al-Absi K. M., Al-Rawashdeh A., Int. J. Agric. Bio. 111 (2009) 266-272.

54. Freihat N. M., Al-Shannag A. K., El Assi N., Int. J. Food Prop. 11 (2008) 561-570.

55. Steven Sibbett G., Ferguson L. Olive production manual, Second edition, University of California, Agriculture and natural resources, Publication 3353, (2005).

56. Velasco J., Dobarganes C., Eur. J. Lipid Sci. Technol. 104 (2002) 661-676.

\section{(2017) ; http://www.jmaterenvironsci.com}

